\title{
openheart Prognostic significance of patent foramen ovale in anticoagulated patients with atrial fibrillation
}

\author{
Rowlens M Melduni (D) ,' Waldemar E Wysokinski, ${ }^{1}$ Zhenzhen Wang, \\ Bernard J Gersh, ${ }^{1}$ Samuel J Asirvatham, ${ }^{1}$ Sri Harsha Patlolla, ${ }^{1}$ Eddie L Greene, ${ }^{2}$ \\ Jae K Oh, ${ }^{1}$ Hon-Chi Lee ${ }^{1}$
}

To cite: Melduni RM,

Wysokinski WE, Wang Z, et al. Prognostic significance of patent foramen ovale in anticoagulated patients with atrial fibrillation. Open Heart 2020;7:e001229. doi:10.1136/ openhrt-2019-001229

Portions of this report have been published in abstract form by the 2018 American Society of Echocardiography 29th Annual Scientific Sessions.

Received 13 December 2019 Revised 26 February 2020 Accepted 9 March 2020
Check for updates

\section{(c) Author(s) (or their} employer(s)) 2020. Re-use permitted under CC BY. Published by BMJ.

${ }^{1}$ Cardiovascular Medicine, Mayo Clinic, Rochester, Minnesota, USA

${ }^{2}$ Medicine, Division of Nephrology and Hypertension, Mayo Clinic College of Medicine, Rochester, Minnesota, USA

Correspondence to Dr Rowlens M Melduni; melduni. rowlens@mayo.edu

\section{ABSTRACT}

Objective Previous studies have postulated a causal role of patent foramen ovale (PF0) in the aetiology of embolic stroke in the general population. We hypothesised that the presence of concomitant PF0 and atrial fibrillation (AF) will add incremental risk of ischaemic stroke to that linked to AF alone.

Methods We analysed data on 3069 consecutive patients (mean age $69.4 \pm 12.2$ years; $67.1 \%$ men) undergoing transoesophageal echocardiography-guided electrical cardioversion (ECV) for AF between May 2000 and March 2012. PF0 was identified by colour Doppler and agitated saline contrast study. All patients were followed up after ECV for first documentation of ischaemic stroke. Outcomes were compared using Cox regression models.

Results The prevalence of PFO was $20.0 \%$ and the shunt direction was left-to-right in the majority of patients (71.4\%). Patients with PFO had a higher frequency of obstructive sleep apnoea ( $21.7 \%$ vs $17.1 \%, p=0.01)$ and higher mean peak left atrial appendage emptying velocity $(38.3 \pm 21.8$ vs $36.1 \pm 20.4 \mathrm{~cm} / \mathrm{s} ; \mathrm{p}=0.04)$ compared with those without PF0. Otherwise, baseline characteristics were similar between groups. During a mean followup period of $7.3 \pm 4.6$ years, 214 patients $(7.0 \%)$ had ischaemic stroke. Multivariable analysis showed no significant association between PF0 and ischaemic stroke (HR, 0.82 (95\% Cl 0.57 to 1.18)). PFO shunt direction was strongly associated with stroke: HR, $1.91(95 \% \mathrm{Cl} 1.16$ to 3.16) for right-to-left shunt and $\mathrm{HR}, 0.58$ (95\% Cl 0.36 to 0.93) for left-to-right shunt.

Conclusions The presence of concurrent PFO in this largely anticoagulated group of patients with AF was not associated with increased risk of ischaemic stroke.

\section{INTRODUCTION}

Patent foramen ovale (PFO) is a common remnant of the foetal circulation that is found in about $25 \%$ to $30 \%$ of the general population. ${ }^{2}$ Previous studies have shown that the presence of a PFO may have a role in the pathogenesis of cerebral and systemic embolism, ostensibly because of paradoxical embolisation from sources within the venous circulation across the atrial right-to-left shunt. ${ }^{3-5}$ Several case-control and population-based

\section{Key questions}

What is already known about this subject?

- The literature suggests that the presence of a patent foramen ovale (PFO) may have a role in the pathogenesis of cerebral and systemic embolism ostensibly because of paradoxical embolisation from sources within the venous circulation across the atrial right-to-left shunt.

- Atrial fibrillation (AF) is also a condition that is linked to ischaemic stroke. Yet, it is not known whether the coexistence of PFO and AF has incremental impact on the risk of ischaemic stroke compared with either condition alone.

What does this study add?

- Although previous studies have postulated a causa role of PF0 in the aetiology of embolic stroke in the general population, in the present study, the presence of PFO in patients with AF was not associated with embolic risk beyond those with right-to-left shunt and other established risk factors in this predominantly anticoagulated AF population. Largescale studies are needed to further examine the impact of PFO and shunt flow direction on clinical outcomes in AF patients.

- The presence of concurrent PF0 does not increase the risk of ischaemic stroke in patients with $\mathrm{AF}$ mainly due to shunt flow at baseline (unprovoked) being directed from left-to-right in the majority of patients with AF.

How might this impact on clinical practice?

- This study's finding of no association of PFO with stroke in patients with AF suggests that in patients with no competitive stroke risks, adequate oral anticoagulation with or without concurrent antiplatelet therapy may suffice to mitigate the purported PFOstroke association.

studies, including a meta-analysis of these studies have reported a significant association between PFO and cryptogenic ischaemic strokes. ${ }^{6-8}$

Similarly, atrial fibrillation (AF) is a condition that is also linked to ischaemic stroke. ${ }^{9}$ 
Despite the recognised increased risk of cerebrovascular events associated with both $\mathrm{PFO}$ and $\mathrm{AF}$, it is not known whether the coexistence of PFO and AF has an incremental impact on the risk of ischaemic stroke. We hypothesise that the concomitant presence of PFO and $\mathrm{AF}$ would pose a larger risk of stroke compared with either condition alone. Therefore, the purpose of this study was to examine whether the presence of a PFO influences the risk of ischaemic stroke in patients with $\mathrm{AF}$.

\section{METHODS}

\section{Study design and population}

We analysed prospectively collected data on all patients who underwent their first transoesophageal echocardiography (TEE)-guided electrical cardioversion for persistent AF at the Mayo Clinic between May 2000 and March $2012(n=3329)$. Patients were excluded if they had a history of congenital heart disease, moderate or greater mitral stenosis, mitral valve surgery or no documented assessment of interatrial shunting $(n=260)$. A total of 3069 patients comprised the study population.

\section{Indirect patient and public involvement}

We did not directly include patient and public involvement (PPI) in this study, but the database used in the study was developed with PPI and is updated by a committee that includes patient representatives.

\section{Echocardiography imaging and electrical cardioversion protocol}

All patients underwent TEE immediately before electrical cardioversion to exclude atrial thrombus, according to a previously described protocol. ${ }^{1011}$ Patients were routinely assessed for PFO and direction of shunt flow at the atrial level according to guidelines of the American Society of Echocardiography. ${ }^{12}$ Sequential interrogation was performed using standard views from 0 to 90 degrees. The colour Doppler scale was reduced to document low-velocity flow across atrial communication if present. Agitated saline combined with provocative physiological manoeuvres was also performed to transiently increase right atrial pressure and provoke right-to-left shunting. Evaluation of left ventricular (LV) ejection fraction and left atrial (LA) enlargement were based on semiquantitative visual assessment by TEE examination.

\section{Definitions}

Patent foramen ovale

A PFO was defined as shunting of blood across the interatrial septum seen on colour flow Doppler and/or the appearance of microbubbles in the LA or LV within three cardiac cycles after opacification of the right atrium with intravenous injection of agitated saline either at rest or after cough, and/or Valsalva release.

\section{Outcome ascertainment}

The primary outcome was ischaemic stroke, determined on the basis of results of radiographic examination, including MRI or CT scan or by physician decision after thorough chart reviews. Stroke outcomes were verified from the health records by cross reference with available administrative databases and outside records, when possible.

\section{Statistical analysis}

Continuous variables are presented as means \pm SD and median (IQR), as appropriate and categorical variables as counts and percentages. Comparisons between groups with and without PFO were performed using the t-test for continuous variables and $\chi 2$ test for categorical variables. Kaplan-Meier survival analyses with log-rank tests were used to estimate cumulative probabilities of ischaemic stroke on the basis of all available follow-up data among PFO and non-PFO groups. Patients who did not experience the event of interest (ischaemic stroke) during follow-up were censored on the follow-up end date or death. A time-dependent Cox proportional hazard regression model was used to estimate the independent association of $\mathrm{PFO}$ and other predictors with ischaemic stroke based on clinical variables at the time of TEE-guided cardioversion. Assessment of prognostic variables was first performed by univariate analysis and baseline covariates with a $\mathrm{p}$ value $\leq 0.10$ were included in the multivariable model. The potential confounding variables included in the multivariable regression model were $\mathrm{CHA}_{2} \mathrm{DS}_{2}$-VASc score (congestive heart failure, hypertension, age $\geq 75$ (doubled), diabetes mellitus, prior stroke or transient ischaemic attack (doubled), vascular disease, age 65 to 74 , female), mean left atrial appendage (LAA) emptying velocity, LAA thrombus, mitral regurgitation ( $\geq$ moderate) and patent foramen ovale. For assessment of the impact of PFO shunt directionality on the risk of stroke, in lieu of patent foramen ovale, the variables 'PFO with right-to-left shunt' and 'PFO with left-to-right shunt' were tested separately versus no PFO. For each variable, HR and $95 \%$ CI were computed. For proportional hazards models, assumptions were tested by analysing main effects and product terms of covariates and time factor transformed to logarithmic scale. Data for ties were approximated using the Efron method. All tests of significance were two-tailed, and an $\alpha$ level of 0.05 was considered the threshold for statistical significance. All statistical analyses were performed using SAS software V.9.4 (SAS Institute Inc, Cary, North Carolina).

\section{RESULTS}

\section{Population characteristics}

Baseline characteristics of the patient population are presented in table 1 . The overall age of the patient population ranged from 18 to 98 years (mean, 69.4 \pm 12.2 ; median (IQR) 71 (62 to 78 ) years), $13.6 \%$ were younger than 55 years of age, $27.0 \%$ were younger than 65 years and $67.1 \%$ were men. The prevalence of PFO among the 3069 patients studied was $20.0 \%$. The PFO shunt flow direction at baseline (ie, unprovoked) was left-to-right in 
Arrhythmias and sudden death

Table 1 Baseline characteristics*

\section{Characteristic}

Demographics

Age, years

Age $>75$ years

Sex (male)

Body mass index, $\mathrm{kg} / \mathrm{m}^{2}$

\section{History variables}

Hypertension

Diabetes mellitus

Prior myocardial infarction

Prior CABG

Stroke or TIA

Congestive heart failure

Cardiomyopathy (tachycardia induced, ischaemic, dilated, infiltrative, restrictive,

hypertrophic or idiopathic)

Smoking (current or former)

Chronic lung disease

Obstructive sleep apnoea

$\mathrm{CHA}_{2} \mathrm{DS}_{2}$-VASc score

Peripheral arterial disease

Preprocedural haemodynamics

Heart rate

Duration of AF episode

$<48$ hour
$>2$ days to $<7$ days
$>7$ days to $<1$ year
$>1$ year

\section{Preprocedural medications}

\begin{tabular}{|c|c|c|c|}
\hline Beta blocker & $1511(61.7)$ & $354(58.1)$ & 0.11 \\
\hline Calcium channel blocker (non-dihydropyridine) & $846(34.5)$ & $188(30.8)$ & 0.08 \\
\hline Statin & $830(33.8)$ & $190(30.9)$ & 0.18 \\
\hline Antiplatelets & $1349(55.0)$ & $337(54.9)$ & 0.98 \\
\hline Warfarin or NOACs & $756(30.8)$ & $202(32.9)$ & 0.32 \\
\hline \multicolumn{4}{|l|}{ Echocardiography } \\
\hline \multicolumn{2}{|l|}{ Patent foramen ovale shunt direction } & & $<0.001$ \\
\hline *No PFO & - & - & - \\
\hline Right-to-left & & \multicolumn{2}{|l|}{$148(24.34)$} \\
\hline Left-to-right & & \multicolumn{2}{|l|}{$434(71.38)$} \\
\hline Left atrial appendage thrombus & $34(1.4)$ & $10(1.6)$ & 0.65 \\
\hline Severe left atrial enlargement & $907(37.0)$ & $210(34.2)$ & 0.20 \\
\hline
\end{tabular}

\begin{tabular}{lll}
\cline { 1 - 1 } No PFO & PFO & \\
\cline { 1 - 1 } $\mathbf{n}=\mathbf{2 4 5 5}(\mathbf{8 0 . 0 \% )}$ & $\mathbf{n}=\mathbf{6 1 4}(\mathbf{2 0 . 0 \% )}$ & P value \\
\hline $69.4 \pm 12.2$ & $69.3 \pm 12.0$ & 0.92 \\
$936(38.1)$ & $219(35.7)$ & 0.26 \\
$1655(67.4)$ & $405(66.0)$ & 0.49 \\
$30.7 \pm 6.8$ & $31.3 \pm 6.9$ & 0.09
\end{tabular}

$\begin{array}{lll}1682(68.8) & 409(66.6) & 0.30 \\ 501(20.5) & 126(20.6) & 0.95 \\ 403(16.6) & 94(15.6) & 0.57 \\ 354(14.5) & 81(13.3) & 0.45 \\ 276(11.2) & 74(12.1) & 0.57 \\ 1041(42.4) & 263(42.8) & 0.85 \\ 584(23.8) & 146(23.8) & 0.99 \\ 1169(47.6) & 308(50.2) & \\ 334(13.7) & 84(13.8) & 0.26 \\ 420(17.1) & 133(21.7) & 0.94 \\ 3.2 \pm 1.6 & 3.2 \pm 1.6 & 0.01 \\ 273(11.1) & 70(11.4) & 0.60 \\ \end{array}$

$\begin{array}{lll}92.9 \pm 22.8 & 92.6 \pm 22.0 & 0.81\end{array}$

$323(15.4)$

63 (12.2)

$585(27.9)$

$155(30.1)$

$1119(53.41)$

$267(51.8)$

$68(3.25)$

$30(5.83)$ 


\section{Table 1 Continued}

\begin{tabular}{|c|c|c|c|}
\hline \multirow[b]{2}{*}{ Characteristic } & \multirow{2}{*}{$\begin{array}{l}\text { No PFO } \\
n=2455(80.0 \%)\end{array}$} & \multirow{2}{*}{$\begin{array}{l}\text { PFO } \\
n=614(20.0 \%)\end{array}$} & \multirow[b]{2}{*}{$P$ value } \\
\hline & & & \\
\hline LV ejection fraction & $51.2 \pm 14.0$ & $51.9 \pm 13.4$ & 0.28 \\
\hline Mitral regurgitation ( $\geq$ moderate) & $631(25.7)$ & $164(26.7)$ & 0.61 \\
\hline \multicolumn{4}{|l|}{ Discharge medications } \\
\hline Beta blocker & $1485(60.8)$ & $349(57.3)$ & 0.11 \\
\hline Calcium channel blocker (non-dihydropyridine) & $457(18.8)$ & $122(20.0)$ & 0.48 \\
\hline Statin & $903(36.8)$ & $203(33.1)$ & 0.08 \\
\hline ACE-I or ARB & $1200(48.9)$ & $272(44.3)$ & 0.04 \\
\hline Antiplatelets & $1286(52.4)$ & $321(52.3)$ & 0.96 \\
\hline Warfarin or NOACs & $2161(88.0)$ & $552(89.9)$ & 0.19 \\
\hline Antiarrhythmics & $829(33.8)$ & $223(36.3)$ & 0.24 \\
\hline Preprocedural INR & $1.9 \pm 0.9$ & $1.9 \pm 0.8$ & 0.39 \\
\hline INR at discharge & $1.9 \pm 0.8$ & $2.0 \pm 0.8$ & 0.72 \\
\hline
\end{tabular}

* denotes reference category

ACE-I, angiotensin-converting enzyme inhibitor; AF, atrial fibrillation; ARB, angiotensin-receptor blocker; CABG, coronary artery bypass grafting; $\mathrm{CHA}_{2} \mathrm{DS}_{2}-\mathrm{VASc}$, congestive heart failure, hypertension, age $\geq 75$ (doubled), diabetes mellitus, prior stroke or transient ischaemic attack (doubled), vascular disease, age 65 to 74, female; INR, international normalised ratio; LA, left atrial; LAA, left atrial appendage; LV, left ventricular; NOACs, novel oral anticoagulants; PFO, patent foramen ovale; TIA, transient ischaemic attack.

$71.4 \%$, right-to-left in $24.3 \%$ and bidirectional in $4.3 \%$ of patients and $46.9 \%$ had provoked right-to-left shunt. Patients with PFO had a higher frequency of obstructive sleep apnoea (OSA) $(21.7 \%$ vs $17.2 \%, \mathrm{p}=0.01)$, a higher mean peak left atrial appendage emptying velocity (LAAEV) $(38.3 \pm 21.8$ vs $36.1 \pm 20.4 \mathrm{~cm} / \mathrm{s}, \mathrm{p}=0.04)$ and a non-significant tendency toward higher body mass index $\left(31.3 \pm 6.9\right.$ vs $\left.30.7 \pm 6.7 \mathrm{~kg} / \mathrm{m}^{2}, \mathrm{p}=0.09\right)$. Otherwise, baseline characteristics including age, sex, prior history of stroke $(12.1 \%$ vs $11.2 \%, \mathrm{p}=0.57), \mathrm{CHA}_{2} \mathrm{DS}_{2}$-VASc score, left ventricular ejection fraction, duration of $\mathrm{AF}$, oral anticoagulation (OAC) therapy and antiplatelet therapy were similar between the two groups.

Cardioversion success rate was not different between patients with $\mathrm{PFO}$ and those without $(99.3 \%$ vs $99.2 \%$, $\mathrm{p}=0.76)$.

\section{Outcomes}

PF0 and ischaemic stroke

Follow-up was complete for all patients. The patients were observed for a mean of $7.3 \pm 4.6$ years. During the follow-up period, $214(7.0 \%)$ patients had ischaemic strokes. In the approximately $10 \%$ of patients who were not discharged on oral anticoagulation, there were $3 / 28$ strokes in the PFO group versus 21/186 strokes in the no-PFO group, $\mathrm{p}=0.10$. Kaplan-Meier survival analysis showed no significant difference in the probability of stroke-free survival between patients with and without PFO $(\log$-rank $\mathrm{p}=0.24)$ (figure 1). Multivariable Cox regression analysis showed no significant association between $\mathrm{PFO}$ and ischaemic stroke in both crude (HR, 0.81 (95\% CI 0.57 to 1.16$)$ ) (table 2) and adjusted analysis (HR, 0.82 (95\% CI 0.57 to 1.18)), respectively. Independent predictors of stroke were $\mathrm{CHA}_{2} \mathrm{DS}_{2}$-VASc score (HR, 1.31, (95\% CI 1.19 to 1.43 )), and LAA thrombus (HR, 2.07, (95\% CI 1.11 to 4.45)) (table 3A).

\section{Shunt flow direction}

Since the PFO shunt flow direction was observed to be left-to-right in the majority of this $\mathrm{AF}$ cohort, we also performed multivariate Cox regression analysis to examine the impact of PFO directionality on the risk of stroke. After adjusting for variables that were significant in univariate analysis, PFO shunt direction had an independent impact on the risk of stroke: (right-to-left,

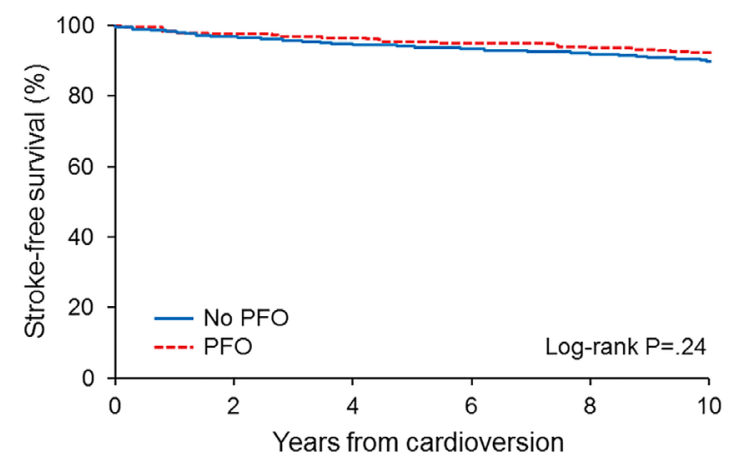

$\begin{array}{rrrrrrr}\text { No. at risk } & & & & & & \\ \text { No PFO } & 2441 & 1935 & 1680 & 1421 & 1117 & 744 \\ \text { PFO } & 608 & 483 & 419 & 361 & 283 & 194\end{array}$

Figure 1 Kaplan-Meier survival analysis showing freedom from ischaemic stroke in patients with versus without PFO. The survival curves show no significant difference in the probability of stroke-free survival between patients with and without PFO. PFO, patent foramen ovale. 
Arrhythmias and sudden death

Table 2 Univariate Cox regression analysis to identify predictors of ischaemic stroke

\begin{tabular}{|c|c|c|}
\hline \multirow[b]{2}{*}{ Characteristic } & \multicolumn{2}{|l|}{ Ischaemic stroke } \\
\hline & HR $(95 \% \mathrm{Cl})$ & $P$ value \\
\hline \multicolumn{3}{|l|}{ Demographics } \\
\hline Age (years) & 1.04 (1.03 to 1.05$)$ & $<0.001$ \\
\hline Age $>75$ years & 1.89 (1.44 to 2.48$)$ & $<0.001$ \\
\hline Sex (male) & 0.74 (0.56 to 0.97$)$ & 0.03 \\
\hline Body mass index & 0.99 (0.97 to 1.01$)$ & 0.37 \\
\hline \multicolumn{3}{|l|}{ History variables } \\
\hline Hypertension & 1.46 (1.08 to 1.98$)$ & 0.02 \\
\hline Diabetes mellitus & 1.13 (0.81 to 1.58$)$ & 0.48 \\
\hline Prior myocardial infarction & 1.46 (1.04 to 2.07$)$ & 0.03 \\
\hline Prior CABG & 1.56 (1.09 to 2.22) & 0.01 \\
\hline Stroke or TIA & 2.54 (1.82 to 3.53 ) & $<0.001$ \\
\hline Congestive heart failure & $1.19(0.90$ to 1.56$)$ & 0.22 \\
\hline Cardiomyopathy & 0.64 (0.45 to 0.92$)$ & 0.02 \\
\hline Smoking (current or former) & 1.00 (0.76 to 1.31$)$ & 0.99 \\
\hline Chronic lung disease & 0.99 (0.64 to 1.52$)$ & 0.95 \\
\hline Obstructive sleep apnoea & $1.02(0.72$ to 1.45$)$ & 0.91 \\
\hline Peripheral arterial disease & 1.46 (0.98 to 2.17$)$ & 0.06 \\
\hline $\mathrm{CHA}_{2} \mathrm{DS}_{2}$-VASc score & 1.32 (1.21 to 1.44$)$ & $<0.001$ \\
\hline \multicolumn{3}{|c|}{ Preprocedural haemodynamics } \\
\hline Heart rate & 1.00 (0.99 to 1.01$)$ & 0.67 \\
\hline Duration of AF episode & - & 0.32 \\
\hline$<48$ hour & 0.97 (0.71 to 1.31$)$ & 0.83 \\
\hline$<24$ hours & 2.72 (0.83 to 8.89 ) & 0.10 \\
\hline 24-48 hours & 2.37 (0.74 to 7.57$)$ & 0.15 \\
\hline$>2$ days to $<7$ days & 2.15 (0.68 to 6.77 ) & 0.19 \\
\hline
\end{tabular}

\section{Preprocedural medications}

\begin{tabular}{|c|c|c|}
\hline Beta blocker & 1.24 (0.93 to 1.64$)$ & 0.14 \\
\hline $\begin{array}{l}\text { Calcium channel blocker } \\
\text { (non-dihydropyridine) }\end{array}$ & $1.45(1.10$ to 1.90$)$ & 0.008 \\
\hline Statin & 0.97 (0.72 to 1.29$)$ & 0.81 \\
\hline ACE-I or ARB & 1.16 (0.88 to 1.52$)$ & 0.29 \\
\hline Antiplatelets & $1.07(0.82$ to 1.40$)$ & 0.64 \\
\hline Warfarin or NOACs & 0.90 (0.68 to 1.22$)$ & 0.52 \\
\hline Antiarrhythmics & 0.81 (0.60 to 1.10$)$ & 0.18 \\
\hline \multicolumn{3}{|l|}{ Echocardiography } \\
\hline Patent foramen ovale & 0.81 (0.57 to 1.16$)$ & 0.24 \\
\hline Patent foramen ovale shunt direction & - & 0.01 \\
\hline *No PFO & - & - \\
\hline Right-to-left & $1.74(1.06-2.86)$ & 0.03 \\
\hline Left-to-right & $0.59(0.36-0.94)$ & 0.03 \\
\hline Bidirectional & 0 & 0.97 \\
\hline Mean LAA emptying velocity & 0.99 (0.98 to 0.996$)$ & 0.003 \\
\hline Spontaneous echo contrast (LA or LAA) & 1.68 (1.24 to 2.27$)$ & $<0.001$ \\
\hline Left atrial appendage thrombus & 2.53 (1.19 to 5.37$)$ & 0.02 \\
\hline Severe left atrial enlargement & 0.95 (0.72 to 1.27$)$ & 0.75 \\
\hline LV ejection fraction & 1.01 (0.99 to 1.02$)$ & 0.37 \\
\hline
\end{tabular}

Table 2 Continued

\begin{tabular}{|c|c|c|}
\hline \multirow[b]{2}{*}{ Characteristic } & \multicolumn{2}{|c|}{ Ischaemic stroke } \\
\hline & HR $(95 \% \mathrm{Cl})$ & $P$ value \\
\hline Mitral regurgitation (>=moderate) & 1.36 (1.02 to 1.81$)$ & 0.04 \\
\hline \multicolumn{3}{|l|}{ Discharge medications } \\
\hline Beta blocker & 1.30 (0.98 to 1.73$)$ & 0.07 \\
\hline $\begin{array}{l}\text { Calcium channel blocker } \\
\text { (non-dihydropyridine) }\end{array}$ & 1.29 (0.94 to 1.78$)$ & 0.12 \\
\hline Statin & 0.95 (0.71 to 1.26$)$ & 0.71 \\
\hline ACE-I or ARB & 1.17 (0.90 to 1.53$)$ & 0.25 \\
\hline Antiplatelets & 0.95 (0.72 to 1.24$)$ & 0.69 \\
\hline Warfarin or NOACs & 1.04 (0.68 to 1.60$)$ & 0.86 \\
\hline Antiarrhythmics & 0.89 (0.66 to 1.18$)$ & 0.41 \\
\hline INR at discharge & 1.03 (0.87 to 1.23$)$ & 0.74 \\
\hline
\end{tabular}

${ }^{*}$ Reference category

ACE-I, angiotensin-converting enzyme inhibitor; AF, atrial fibrillation; ARB, angiotensin-receptor blocker; CABG, coronary artery bypass grafting; $\mathrm{CHA}_{2} \mathrm{DS}_{2}-\mathrm{VASc}$, congestive heart failure, hypertension, age $\geq 75$ (doubled), diabetes mellitus, prior stroke or transient ischaemic attack (doubled), vascular disease, age 65 to 74, female; INR, international normalised ratio; LA, left atrial; LAA, left atrial appendage; LV, left ventricular; NOACs, novel oral anticoagulants; PFO, patent foramen ovale; TIA, transient ischaemic attack.

HR: 1.91 (1.16 to 3.16); left-to-right, HR: 0.58 (0.36 to 0.93) (table 3B). Kaplan-Meier survival analysis showed a lower probability of stroke-free survival in patients with right-to-left shunting and a higher stroke-free survival in those with left-to-right shunting compared with patients without PFO (log-rank $p=0.005)$. The group with bidirectional shunt was relatively small $(\mathrm{n}=26)$ and had a limited number of events during follow-up, making it difficult to generate any clinically reliable conclusion (figure 2 ).

\section{DISCUSSION \\ Main findings}

To our knowledge, this is the first study to date to assess the incremental effect of PFO on the risk of adverse cerebrovascular events in patients with AF. In this study of patients with AF referred for TEE-guided electrical cardioversion, the principal findings are (1) that the presence of a concurrent PFO does not increase the risk of

Table 3A Multivariate Cox regression analysis to identify predictors of ischaemic stroke

\begin{tabular}{llc}
\hline \multirow{2}{*}{ Covariates } & \multicolumn{2}{l}{ Ischaemic stroke $\mathbf{2 1 4} \mathbf{( 7 . 0 \% )}$} \\
\cline { 2 - 3 } & HR (95\% Cl) & P value \\
\hline Patent foramen ovale & $0.82(0.57$ to 1.18$)$ & 0.50 \\
CHA $_{2}$ DS $_{2}$-VASc score & $1.31(1.19$ to 1.43$)$ & $<0.001$ \\
Mean LAA emptying velocity $^{-5}$ & $1.04(1.00$ to 1.08$)$ & 0.07 \\
LAA thrombus & $2.07(1.11$ to 4.45$)$ & 0.03 \\
\hline
\end{tabular}

$\mathrm{CHA}_{2} \mathrm{DS}_{2}$-VASc, congestive heart failure, hypertension, age $\geq 75$ (doubled), diabetes mellitus, prior stroke or transient ischaemic attack (doubled), vascular disease, age 65 to 74, female; LAA, left atrial appendage. 
Table 3B Multivariate Cox regression analysis to assess the independent impact of PFO shunt flow direction on the risk of ischaemic stroke

\begin{tabular}{|c|c|c|}
\hline \multirow[b]{2}{*}{ Covariates } & \multicolumn{2}{|c|}{ Ischaemic stroke 214 (7.0\%) } \\
\hline & HR (95\% Cl) & $P$ value \\
\hline \multicolumn{3}{|c|}{ Patent foramen ovale shunt direction } \\
\hline Right-to-left & 1.91 (1.16 to 3.16$)$ & 0.01 \\
\hline Left-to-right & $0.58(0.36$ to 0.93$)$ & 0.02 \\
\hline Bidirectional & 0 & 0.97 \\
\hline No PFO* & - & - \\
\hline $\mathrm{CHA}_{2} \mathrm{DS}_{2}$-VASc score & 1.31 (1.20 to 1.43$)$ & $<0.001$ \\
\hline Mean LAA emptying velocity ${ }^{-5}$ & 1.03 (0.99 to 1.07$)$ & 0.08 \\
\hline LAA thrombus & 1.75 (1.09 to 3.19$)$ & 0.03 \\
\hline \multicolumn{3}{|c|}{$\begin{array}{l}\text { * denotes reference category } \\
\mathrm{CHA}_{2} \mathrm{DS}_{2}-\mathrm{VASc} \text {, congestive heart failure, hypertension, age } \geq 75 \\
\text { (doubled), diabetes mellitus, prior stroke or transient ischaemic } \\
\text { attack (doubled), vascular disease, age } 65 \text { to } 74 \text {, female; LAA, left } \\
\text { atrial appendage; PFO, patent foramen ovale. }\end{array}$} \\
\hline
\end{tabular}

ischaemic stroke in patients with $\mathrm{AF}$, (2) only traditional risk factors such as $\mathrm{CHA}_{2} \mathrm{DS}_{2}$-VASc score, LAA thrombus, in addition to shunt flow direction were independently associated with ischaemic stroke, (3) unprovoked left-toright shunting at the atrial level predominated at baseline and had a protective effect against stroke in patients with $\mathrm{AF}$ while right-to-left shunting was associated with an increased risk of stroke in patients with AF.

The prevalence of PFO in the general population has been estimated to be $25 \%$ to $33 \% .{ }^{31314}$ In our study, the prevalence of $\mathrm{PFO}$ was $20 \%$, which is slightly lower than that in the general population, but comparable with that of previous studies showing that the frequency of



$\begin{array}{rrrrrrr}\text { No. at risk } & & & & & & \\ \text { No PFO } & 2441 & 1935 & 1680 & 1421 & 1117 & 744 \\ \text { R-L Shunt } & 147 & 105 & 87 & 79 & 64 & 44 \\ \text { L-R Shunt } & 429 & 356 & 314 & 265 & 205 & 138 \\ \text { Bi-dir Shunt } & 26 & 19 & 15 & 14 & 12 & 10\end{array}$

Figure 2 Kaplan-Meier survival analysis showing freedom from ischaemic stroke stratified by shunt flow direction versus no PFO. Patients with right-to-left shunting had a lower probability of stroke-free survival and those with leftto-right shunting had a higher stroke-free survival than did patients without PFO (log-rank $p=0.005)$. Bi-dir, bidirectional; L-R, left-to-right; PFO, patent foramen ovale; $R-L$, right-toleft.
PFO declines steadily with advancing age,${ }^{14} 15$ likely due to higher prevalence of cardiovascular conditions that can increase LA pressure in the AF population. ${ }^{10}$ Our results also validate previous findings on risk factors for ischaemic stroke and suggest that asymptomatic PFOs, specifically with left-to-right shunting, in anticoagulated patients with AF are of uncertain clinical significance and do not appear to require immediate intervention beyond standard therapy for AF.

\section{Comparison with previous studies}

The scientific literature is discordant on the relationship between PFO and ischaemic stroke. Although prior studies have shown an association of PFO with stroke in young patients without identifiable cause, ${ }^{3}{ }^{14}$ the impact of PFO on stroke risk in the elderly population remains controversial. Some earlier studies have shown a significant increase in the risk of stroke,$^{15}{ }^{16}$ whereas others have not. ${ }^{217} \mathrm{Di}$ Tullio et $a l^{17}$ examined the relationship between PFO and risk of ischaemic stroke in the Northern Manhattan Study cohort using transthoracic echocardiography with contrast injection in 1100 stroke-free subjects over 39 years (mean $68.7 \pm 10$ years). Participants were followed up annually to ascertain the outcome of ischaemic stroke. The observed prevalence of PFO was $14.9 \%$. Similar to our study (mean age $69.4 \pm 12.2$ years), during a mean follow-up of $79.7 \pm 28.0$ months, the stroke-free survival did not differ between patients with and without a PFO. Likewise, Meissner et $a l^{2}$ showed that $\mathrm{PFO}$ was not an independent risk factor for future cerebrovascular events in the SPARC study, a prospective, population-based study of 577 randomly sampled participants at least 45 years old (mean, $70 \pm 13$ years).

By contrast, Homma et $a l^{16}$ retrospectively assessed the effect of age on the risk of recurrent ischaemic stroke or death over a 2-year follow-up period in a subset of 250 patients enrolled in the PFO in Cryptogenic Stroke Study who were treated medically for cryptogenic stroke. They showed a significant correlation between the presence of PFO and the risk of recurrent stroke in patients 65 years and older, but not in patients less than $<55$ or in patients 55 to 64 years. However, this study was limited by small sample size and low number of clinical events.

\section{Proposed mechanisms}

Role of PFO shunt flow direction

It must be emphasised that PFO-related shunt directionality may play a major role in the risk of stroke. Prior studies have shown that patients with cryptogenic stroke have larger PFO and more extensive right-to-left shunt flow than patients with stroke of determined cause. ${ }^{8}{ }^{18}$ Although our study confirmed the impact of PFO-related shunt directionality, the dominant direction of interatrial shunting at baseline (ie, unprovoked) observed in this AF population was left-to-right, presumably due to the left-to-right atrial pressure gradient through the $\mathrm{PFO}$, consistent with the higher mean LAAEV observed in the group with PFO versus those without PFO. Indeed, patients with AF are known to have 
an increased burden of cardiovascular diseases, such as hypertension, and peripheral vascular diseases and are therefore more vulnerable to developing diastolic dysfunction and elevated LA pressure. ${ }^{10} 1119$

\section{Lack of association of PFO with ischaemic stroke}

After birth, the foramen ovale closes functionally as pulmonary vascular resistance decreases and allows pressure in the LA to exceed that in the right atrium. A similar process appears to manifest in the elderly due to changes in loading conditions. ${ }^{1}$ It is also possible that elevated LA pressure due to loss of LV compliance, which often coexists with AF in the elderly population, ${ }^{20}$ could theoretically limit right-to-left shunting. Subsequent late spontaneous fusion or functional closure of PFOs in this patient population could also paradoxically eliminate the risk of paradoxical embolism as a mechanism of stroke. ${ }^{21}$

\section{Role of anticoagulation}

Previous studies have shown that treatment of PFO with OAC therapy may mitigate the PFO-stroke association. ${ }^{22} 23$ The vast majority of patients in our study (approximately $90 \%$ ) received oral anticoagulation therapy, and $50 \%$ of the patients were prescribed additional antiplatelet therapy at discharge, essentially eliminating the major mechanism for stroke (paradoxical embolisation) by preventing thrombus formation. ${ }^{24}$ More recent studies, including the RESPECT trial, suggest that $\mathrm{PFO}$ closure in patients with no competitive stroke risks prevents strokes equally well but not better than $\mathrm{OAC},{ }^{25}$ but it avoids the bleeding risk of OAC and may be the treatment of choice. ${ }^{26}$ PFO closure may be another viable therapeutic option as it can confer collateral benefits, particularly in such patients with right-to-left shunt as well as those with OSA, including improved sleepdisordered breathing and nocturnal arterial oxygenation, reduced nocturnal blood pressure, attenuation of endothelial dysfunction and vascular stiffening and improvement of left ventricular diastolic function. ${ }^{27} 28$

\section{Clinical implications}

In the current study, the finding of no association of PFO with stroke in patients with $\mathrm{AF}$ suggests that adequate OAC with or without concurrent antiplatelet therapy may suffice to mitigate the purported PFO-stroke association. Although OAC is a physiologically attractive medical therapy to prevent recurrent stroke in patients with a PFO, it is not clear whether PFOs detected incidentally in patients without prior history of embolic events comprise an indication for preventive treatment. The more interesting question of whether a PFO may increase the stroke risk in AF patients who are not on anticoagulation could not be addressed by this study.

\section{LIMITATIONS}

Our data are based on a single-centre experience, and a number of limitations should be taken into consideration for a correct interpretation of results. The study was non-randomised and therefore we cannot preclude the presence of unidentified confounders. However, the study data were collected prospectively from both groups, and all the TEE-guided electrical cardioversions were performed in the same time period, therefore, confounding factors such as advances in technology and operator experience were eliminated. Although both groups were similarly studied by TEE with the use of colour Doppler and saline contrast imaging, clinical risk factors that could potentially enhance the effect of PFO on the risk of paradoxical embolism, such as PFO size, ${ }^{8} 1824$ atrial septal aneurysm, ${ }^{29}$ deep vein thrombosis ${ }^{30}$ and hypercoagulability ${ }^{24}$ were not recorded. However, this limitation would likely bias in favour of an association of $\mathrm{PFO}$ with stroke. It is also possible that $\mathrm{PFO}$ was underdiagnosed in the non-PFO group, therefore biassing the study toward the null hypothesis. However, the two groups of patients analysed were homogeneous and similar imaging methodology and diagnostic criteria were employed across all patients, such that the effect should be balanced between both groups. Despite the very high rate of OAC prescription at discharge, the rate of stroke could be underestimated as information on anticoagulation status during follow-up was not collected. However, both groups had similar $\mathrm{CHA}_{2} \mathrm{DS}_{2}$-VASC score and were therefore equally likely to continue OAC therapy during follow-up.

\section{CONCLUSIONS}

The presence of $\mathrm{PFO}$ in patients with $\mathrm{AF}$ was not associated with embolic risk beyond those with right-to-left shunt and other established risk factors in this predominantly anticoagulated $\mathrm{AF}$ population. Large-scale studies are needed to further examine the impact of $\mathrm{PFO}$ and shunt flow direction on clinical outcomes in $\mathrm{AF}$ patients.

Contributors All authors contributed to the conception, design of the study or the acquisition, analysis or interpretation of data, funding acquisition, drafting the manuscript or revising it critically for important intellectual content and gave final approval of the final version of the manuscript.

Funding RM is supported by National Institutes of Health (NIH) K01 (HL 135288). Competing interests None declared.

Patient consent for publication Not required.

Ethics approval Approval was provided by the Mayo Clinic Institutional Review Board, Rochester, Minnesota, USA.

Provenance and peer review Not commissioned; externally peer reviewed.

Data availability statement Data are available upon reasonable request. Deidentified participant data are available upon reasonable request.

Open access This is an open access article distributed in accordance with the Creative Commons Attribution 4.0 Unported (CC BY 4.0) license, which permits others to copy, redistribute, remix, transform and build upon this work for any purpose, provided the original work is properly cited, a link to the licence is given, and indication of whether changes were made. See: https://creativecommons.org/ licenses/by/4.0/.

ORCID iD

Rowlens M Melduni http://orcid.org/0000-0001-7074-6164 


\section{REFERENCES}

1 Hagen PT, Scholz DG, Edwards WD. Incidence and size of patent foramen ovale during the first 10 decades of life: an autopsy study of 965 normal hearts. Mayo Clin Proc 1984;59:17-20.

2 Meissner I, Khandheria BK, Heit JA, et al. Patent foramen ovale: innocent or guilty? Evidence from a prospective population-based study. J Am Coll Cardiol 2006;47:440-5.

3 Lechat P, Mas JL, Lascault G, et al. Prevalence of patent foramen ovale in patients with stroke. N Engl J Med 1988;318:1148-52.

4 Mas JL, Arquizan C, Lamy C, et al. Recurrent cerebrovascular events associated with patent foramen ovale, atrial septal aneurysm, or both. N Engl J Med 2001;345:1740-6.

5 Webster MW, Chancellor AM, Smith HJ, et al. Patent foramen ovale in young stroke patients. Lancet 1988;2:11-12.

6 Mazzucco S, Li L, Binney L, et al. Prevalence of patent foramen ovale in cryptogenic transient ischaemic attack and non-disabling stroke at older ages: a population-based study, systematic review, and meta-analysis. Lancet Neurol 2018;17:609-17.

7 Handke M, Harloff A, Olschewski M, et al. Patent foramen ovale and cryptogenic stroke in older patients. $N$ Engl J Med 2007;357:2262-8.

8 Homma S, Di Tullio MR, Sacco RL, et al. Characteristics of patent foramen ovale associated with cryptogenic stroke. A biplane transesophageal echocardiographic study. Stroke 1994;25:582-6.

9 Wolf PA, Abbott RD, Kannel WB. Atrial fibrillation as an independent risk factor for stroke: the Framingham study. Stroke 1991;22:983-8.

10 Melduni RM, Lee H-C, Bailey KR, et al. Real-Time physiologic biomarker for prediction of atrial fibrillation recurrence, stroke, and mortality after electrical cardioversion: a prospective observational study. Am Heart J 2015;170:914-22.

11 Melduni RM, Gersh BJ, Wysokinski WE, et al. Real-Time pathophysiologic correlates of left atrial appendage thrombus in patients who underwent Transesophageal-Guided electrical cardioversion for atrial fibrillation. Am J Cardiol 2018;121:1540-7.

12 Silvestry FE, Cohen MS, Armsby LB, et al. Guidelines for the echocardiographic assessment of atrial septal defect and patent foramen ovale: from the American Society of echocardiography and Society for cardiac angiography and interventions. J Am Soc Echocardiogr 2015;28:910-58.

13 Benjamin EJ, Levy D, Vaziri SM, et al. Independent risk factors for atrial fibrillation in a population-based cohort. The Framingham heart study. JAMA 1994;271:840-4.

14 Di Tullio M, Sacco RL, Gopal A, et al. Patent foramen ovale as a risk factor for cryptogenic stroke. Ann Intern Med 1992;117:461-5.

15 de Belder MA, Tourikis L, Leech G, et al. Risk of patent foramen ovale for thromboembolic events in all age groups. Am J Cardiol 1992;69:1316-20.
16 Homma S, DiTullio MR, Sacco RL, et al. Age as a determinant of adverse events in medically treated cryptogenic stroke patients with patent foramen ovale. Stroke 2004;35:2145-9.

17 Di Tullio MR, Sacco RL, Sciacca RR, et al. Patent foramen ovale and the risk of ischemic stroke in a multiethnic population. J Am Coll Cardiol 2007;49:797-802.

18 Steiner MM, Di Tullio MR, Rundek T, et al. Patent foramen ovale size and embolic brain imaging findings among patients with ischemic stroke. Stroke 1998;29:944-8.

19 Melduni RM, Suri RM, Seward JB, et al. Diastolic dysfunction in patients undergoing cardiac surgery: a pathophysiological mechanism underlying the initiation of new-onset post-operative atrial fibrillation. J Am Coll Cardiol 2011;58:953-61.

20 Redfield MM, Jacobsen SJ, Borlaug BA, et al. Age- and genderrelated ventricular-vascular stiffening: a community-based study. Circulation 2005;112:2254-62.

21 Siostrzonek P, Lang W, Zangeneh M, et al. Significance of leftsided heart disease for the detection of patent foramen ovale by transesophageal contrast echocardiography. J Am Coll Cardiol 1992;19:1192-6.

22 Kent DM, Dahabreh IJ, Ruthazer R, et al. Anticoagulant vs. antiplatelet therapy in patients with cryptogenic stroke and patent foramen ovale: an individual participant data meta-analysis. Eur Heart J 2015;36:2381-9.

23 Kitsios GD, Dahabreh IJ, Abu Dabrh AM, et al. Patent foramen ovale closure and medical treatments for secondary stroke prevention: a systematic review of observational and randomized evidence. Stroke 2012;43:422-31.

24 Telman G, Yalonetsky S, Kouperberg E, et al. Size of PFO and amount of microembolic signals in patients with ischaemic stroke or TIA. Eur J Neurol 2008;15:969-72.

25 Saver JL, RESPECT Trial Steering Committee. Trials of patent foramen ovale closure. N Engl J Med 2017;377:2600.

26 Søndergaard L, Kasner SE, Rhodes JF, et al. Patent foramen ovale closure or antiplatelet therapy for cryptogenic stroke. N Engl J Med 2017;377:1033-42

27 Rimoldi SF, Ott SR, Rexhaj E, et al. Effect of patent foramen ovale closure on obstructive sleep apnea. J Am Coll Cardiol 2015;65:2257-8.

28 Rimoldi SF, Ott S, Rexhaj E, et al. Patent foramen ovale closure in obstructive sleep apnea improves blood pressure and cardiovascular function. Hypertension 2015;66:1050-7.

29 Mattioli AV, Aquilina M, Oldani A, et al. Atrial septal aneurysm as a cardioembolic source in adult patients with stroke and normal carotid arteries. A multicentre study. Eur Heart J 2001;22:261-8.

30 Cramer SC, Rordorf G, Maki JH, et al. Increased pelvic vein thrombi in cryptogenic stroke: results of the paradoxical emboli from large veins in ischemic stroke (pelvis) study. Stroke 2004;35:46-50. 